\title{
GLIFOSATO: PROPRIEDADES, TOXICIDADE, USOS E LEGISLAÇÃO
}

Ozelito Possidônio de Amarante Junior* e Teresa Cristina Rodrigues dos Santos

Departamento de Tecnologia Química, Universidade Federal do Maranhão, Av. dos Portugueses, s/n, 65080-040 São Luís - MA Natilene Mesquita Brito e Maria Lúcia Ribeiro

Instituto de Química, Universidade Estadual Paulista, Rua Prof. Francisco Degni, s/n, 14800-900 Araraquara - SP

Recebido em 24/4/01; aceito em 24/10/01

GLYPHOSATE: PROPERTIES, TOXICITY, USE AND LEGISLATION. This paper supplies a compact revision on the herbicide glyphosate physic-chemistry characteristic mains, including toxicity and valid Brazilian legislation for its use.

Keywords: glyphosate; physic-chemistry characteristic; toxicity: legislation.

\section{INTRODUÇÃO}

O comércio mundial de pesticidas cresce a cada ano. Embora muitas mudanças e inovações surjam conforme as necessidades do mercado, entre elas o advento das culturas transgênicas, resistentes a algumas pragas, o uso de herbicidas é destacado visto que a maioria destas inovações não impede o florescimento de ervas daninhas no campo. Atualmente, o herbicida glifosato ( $\mathrm{N}$-(fosfonometil)glicina), não-seletivo, sistêmico, pós-emergente, representa $60 \%$ do mercado mundial de herbicidas não seletivos, contabilizando um total de US\$ 1,2 bilhão/ano com vendas do produto ${ }^{1}$.

Glifosato apresenta elevada eficiência na eliminação de ervas daninhas. Desde 1971, quando foi relatado primeiramente como herbicida, três tipos de glifosato vêm sendo comercializados: glifosato-isopropilamônio, glifosato-sesquisódio (patenteados por Monsanto e vendido como Round-up), e glifosato-trimesium (patenteado por ICI, atual Syngenta). Seja como sal de amônio ou sódio, glifosato é um organofosfato que não afeta o sistema nervoso da mesma maneira que outros organofosforados (em geral inseticidas, inibidores da enzima colinesterase). Apesar do glifosato ser citado como pouco tóxico, há evidências de efeitos deletérios no ambiente, principalmente devido à resistência adquirida por algumas espécies de ervas, após o uso prolongado do herbicida ${ }^{1}$.

Em diversos tipos de cultivo, glifosato costuma ser pulverizado sendo, em geral, absorvido na planta através de suas folhas e dos caulículos novos. O herbicida é, então, transportado por toda a planta, agindo nos vários sistemas enzimáticos, inibindo o metabolismo de aminoácidos. As plantas tratadas com glifosato morrem lentamente, em poucos dias ou semanas e, devido ao transporte por todo o sistema, nenhuma parte da planta sobrevive ${ }^{1}$.

As concentrações mais altas de glifosato e seu metabólito, o ácido aminometilfosfônico (AMPA), tem sido encontradas em folhagens novas. A aplicação de glifosato pode resultar na presença de resíduos tanto na colheita quanto em animais usados na alimentação humana. No ambiente, as concentrações mais altas de ambos os compostos foram encontradas no solo. A ocorrência de glifosato em água subterrânea foi citada uma única vez, no estado do Texas, EUA, reportada por Hallberg (1989), mas a concentração medida não foi especificada. A aplicação direta como herbicida em águas superfici-

\footnotetext{
*e-mail: ozelito@hotmail.com
}

ais pode ser responsável pela presença de glifosato em água potá$\mathrm{vel}^{2}$.

Considerando-se a ampla utilização do glifosato em todo o mundo, torna-se importante um estudo de suas propriedades físico-químicas, interações com componentes da água e do solo, bem como sua detecção e quantificação em amostras naturais. Este artigo pretende discutir as principais características físicas e químicas, que conferem ao herbicida um comportamento peculiar e distinto da maioria dos pesticidas usualmente estudados.

\section{PROPRIEDADES FÍSICO-QUÍMICAS}

O glifosato tem fórmula molecular $\mathrm{C}_{3} \mathrm{H}_{8} \mathrm{NO}_{5} \mathrm{P}(\mathrm{m} . \mathrm{m} .=169,1 \mathrm{~g}$ / mol) e, na forma de sal de isopropilamônio, apresenta-se acrescido do grupo $\left(\mathrm{CH}_{3}\right)_{2} \mathrm{CHNH}_{3}{ }^{+}(\mathrm{m} . \mathrm{m} .=228,2 \mathrm{~g} / \mathrm{mol})^{3}$. Em condições ambientais, tanto glifosato quanto seus sais são sólidos cristalinos, muito solúveis em água ( $12 \mathrm{~g} / \mathrm{L}$ a $25^{\circ} \mathrm{C}$, para glifosato) e quase insolúveis em solventes orgânicos comuns, tais como acetona e etanol, entre outros. Glifosato funde a $200{ }^{\circ} \mathrm{C}$, possui densidade aparente de $0,5 \mathrm{~g} / \mathrm{cm}^{3}$ e se apresenta bastante estável em presença de luz, inclusive em temperaturas superiores a $60{ }^{\circ} \mathrm{C}^{3}$. Os valores de $\mathrm{pK}$ encontrados na literatura ${ }^{3-6}$ para o glifosato são: $\mathrm{pK}_{1}=0,8 ; \mathrm{pK}_{2}=2,16 ; \mathrm{pK}_{3}=$ 5,$46 ; \mathrm{pK}_{4}=10,14$. Tais constantes de dissociação indicam o grau de dissociação do herbicida em função do $\mathrm{pH}$, conforme pode ser observado na Figura 1.

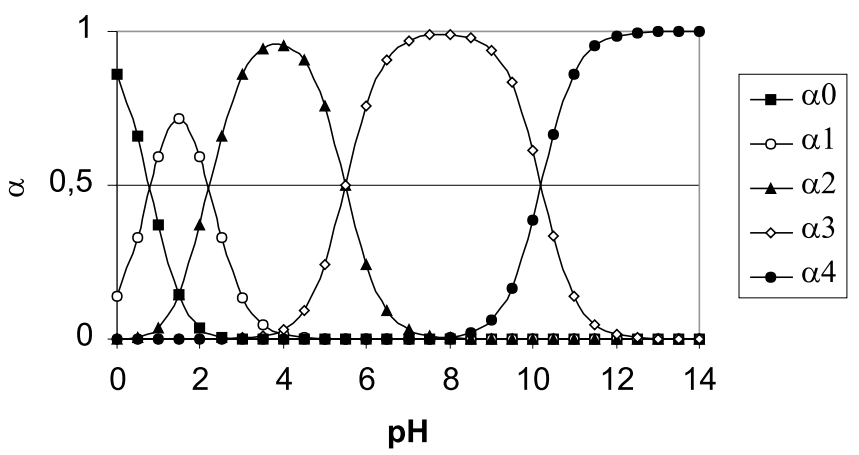

Figura 1. Grau de dissociação do glifosato construído a partir dos valores de $K_{a}\left(a_{0}\right.$, composto com uma protonação; $a_{l}$, composto apresentando uma dissociação; $a_{2}$, molécula com duas dissociações; $a_{3}$, molécula com três dissociações; $a_{4}$, composto totalmente dissociado) 
No gráfico, em pH abaixo de 0,8 , a maior parte do glifosato se apresenta com uma protonação no sítio da amina. Em pH 0,8, valor da primeira constante, tem-se $50 \%$ das moléculas possuindo esta protonação e as demais moléculas com uma dissociação no grupo fosfato. A partir deste valor até $\mathrm{pH} 2,2$, tem-se predominância da forma molecular, com uma dissociação $\left(-\mathrm{PO}_{2} \mathrm{H}^{-}\right)$e uma protonação $\left(-\mathrm{NH}_{2}^{+}-\right.$), sendo que, em pH 2,2, 50\% do composto já possuirá duas dissociações, embora mantenha a protonação no grupamento amina. Entre $\mathrm{pH}$ 2,2 e 5,4, o herbicida se mostra com predominância da forma com duas dissociações, tendo, do mesmo modo, $50 \%$ das moléculas com três dissociações em pH 5,5. A partir de pH 5,5 até 10,2 , têm-se três dissociações. Neste $\mathrm{pH}$ ocorrem as formas com três e quatro dissociações e, então, o glifosato se apresenta totalmente dissociado acima de $\mathrm{pH} 11$.

Aminoácidos e derivados apresentam comportamento zwiteriônico, ou seja, em sua estrutura o grupo carboxílico apresenta caráter mais fortemente ácido que o grupo amônio. No caso do glifosato, os grupos fosfato e carboxílico têm maior caráter ácido que o amônio ${ }^{7}$. Cikalo, Goodall e Mathews ${ }^{8}$ consideram o comportamento zwinteriônico do glifosato quando descrevem sua dissociação. Neste caso, nas primeiras dissociações, o glifosato perderia os hidrogênios ligados a oxigênio, e apenas na última dissociação aquele ligado ao nitrogênio. Desta forma, as etapas de dissociação previstas são as apresentadas na Figura 2.<smiles>O=C(O)CNCP(=O)(O)O</smiles><smiles>COP(=O)(O)CNCC(=O)[O-]</smiles><smiles>COP(=O)(CNCC(=O)[O-])OC</smiles><smiles>COP(=O)([O-])CNCC(=O)[O-]</smiles>

Figura 2. Dissociação do glifosato de acordo com seu comportamento zwiteriônico

\section{USO}

Desde que foi introduzido no mercado, o uso do glifosato se tornou prática freqüente. Em geral, glifosato é vendido em concentrações de $48 \%$ (m/v) e as doses aplicadas são em torno de $5 \mathrm{~L} / \mathrm{ha}^{9}$.

Glifosato é indicado no controle de ervas daninhas anuais e perenes, monocotiledôneas ou dicotiledôneas, em culturas de arroz irrigado, cana-de-açúcar, café, citros, maçã, milho, pastagens, soja (plantio direto ou indireto), fumo, uva e soqueira em cana-de-açúcar. É indicado, ainda, para as culturas de ameixa, banana, cacau, nectarina, pêra, pêssego, seringueira e plantio direto do algodão ${ }^{10}$. A mistura com outros herbicidas pode reduzir a atividade do produto, ocasionando o chamado antagonismo. Para aumentar a eficiência na eliminação de ervas, pode-se utilizar glifosato misturado com outros herbicidas, tais como formulados à base de 2,4-D, terbutilazina, simazina, alaclor e diuron, por exemplo ${ }^{11}$. Glifosato pode, ainda, ser aplicado na água ${ }^{1}$ para o controle de ervas aquáticas.

O número de aplicações feitas com glifosato costuma variar de acordo com as ervas a serem tratadas. Para plantas daninhas perenes, no início da floração, ou para ervas daninhas anuais, antes da floração e formação de sementes, a aplicação é feita em dose única. Para tiririca (Cyperus rotundus ou Cyperus difformes), devido à sua fisiologia, são necessárias 3 a 4 aplicações, em intervalos de 20 a 40 dias. Entretanto, no caso da Digitaria sanguinales, o controle é feito em plantas recentemente germinadas até a fase adulta. Apesar da elevada eficiência, glifosato não tem ação sobre as sementes das ervas no solo e, portanto, deve ser aplicado quando as espécies a serem eliminadas estão em condições de desenvolvimento, sem efeito de estresse hídrico (solo seco) ${ }^{1}$.

Para as culturas de maçã, uva e citros, a aplicação do herbicida é feita em área total (técnica do coroamento) ou somente onde houver manchas de mato. Para culturas de café, cana-de-açúcar, soja e milho, no entanto, a aplicação é feita somente nas entrelinhas. Em pastagens, a aplicação é realizada nas reboleiras de mato, ou durante o pré-plantio, no caso de formação de pastagem artificial. Para cultivo de arroz e soja, em plantio direto ou indireto, glifosato é aplicado antes da semeadura da cultura ${ }^{11}$. Em culturas de eucalipto/pinus a aplicação é feita em pós-emergência, em pleno estágio vegetativo do mato, nas entrelinhas, após a implantação das espécies florestais ou, ainda, no pré-plantio, para garantir a eliminação da vegetação da área $^{12}$. No cultivo de pequenas áreas, glifosato pode ser aplicado em pré-plantio da cultura e pós-emergência das plantas daninhas. Para não atingir as partes verdes das plantas úteis (folhas, ramos ou caules jovens), glifosato deve ser preferencialmente aplicado com jato dirigido $^{13}$. A "calda" pronta do formulado é altamente corrosiva. Por este motivo, ele não deve ser armazenado em recipientes de ferro galvanizado, ferro ou aço comum ${ }^{11}$.

\section{TOXICIDADE AGUDA}

A toxicidade aguda deste pesticida é considerada baixa ${ }^{3}$. De acordo com a Organização Mundial da Saúde (WHO), o $\mathrm{LD}_{50}$ oral do glifosato puro em ratos é de $4.230 \mathrm{mg} / \mathrm{kg}$, enquanto que o fabricante (Monsanto) ${ }^{1}$ cita $\mathrm{LD}_{50}$ de $5.600 \mathrm{mg} / \mathrm{kg}$. A toxicidade relativamente baixa pode ser atribuída à modalidade bioquímica de ação do glifosato em um caminho metabólico nas plantas (chamado mecanismo do ácido "shikimico"), similar ao existente em alguns microorganismos mais complexos, não existindo, entretanto, em animais. O glifosato pode, no entanto, impedir a ação de funções enzimáticas nos animais. Quando injetado no abdômen de ratos, causou diminuição da atividade de algumas enzimas ${ }^{1}$.

Apesar da toxicidade relativamente baixa do glifosato, alguns dos componentes de seus produtos formulados apresentam-na mais 
elevada que o ingrediente ativo. As formulações encontradas no mercado contêm, geralmente, surfactante, cuja finalidade é impedir a formação de gotas e o alcance de áreas além das folhas que são pulverizadas. Alguns destes são irritantes sérios, tóxicos para peixes ${ }^{1}$. Os tipos mais extensamente usados em formulações do glifosato são as etilaminas. Os compostos deste grupo de surfactantes são significativamente mais tóxicos do que o glifosato, causando sérias irritações nos olhos, sistema respiratório e pele. Devido ao potencial irritante e tóxico destas substâncias, novos surfactantes têm sido desenvolvidos e produtos com estas novas formulações vêm sendo vendidos, com aprovação dos órgãos de fiscalização competentes ${ }^{1}$

\section{TOXICIDADE CRÔNICA}

Embora a toxicidade aguda do glifosato seja considerada baixa, alguns autores ${ }^{1-3}$ têm sugerido que o herbicida pode causar defeitos crônicos de nascimento em determinadas espécies de animais, quando administrado em doses elevadas e por um período prolongado. A dose diária aceitável por massa corpórea deste composto é relativamente baixa ( $\mathrm{ADI}=$ 0,05 mg.Kg-1. $\mathrm{d}^{-1}$ ). Os estudos crônicos de alimentação não mostraram perda de peso, efeitos ao sangue e pâncreas ou, ainda, evidência de carcinogenicidade nos seres humanos. No entanto, estudos feitos com ratos demonstraram perda de peso, descarga nasal e morte de matrizes grávidas, além de desordens digestivas ${ }^{1}$.

Em plantas, o glifosato apresenta grande toxicidade, exceto em caules suberizados. Entre os efeitos agudo e crônico em seres humanos, são citados: dermatite de contato e síndrome tóxica após a ingestão de doses elevadas (epigastralgia, ulceração ou lesão de mucosa gástrica, hipertermia, anúria, oligúria, hipotensão, conjuntivite, edema orbital, choque cardiogênico, arritmias cardíacas, edema pulmonar não-carcinogênico, pneumonite, necrose tubular aguda, elevação de enzimas hepáticas, aumento da quantidade de leucócitos, acidose metabólica e hipercalemia ${ }^{14}$. Em ambientes aquáticos, a toxicidade do glifosato é acentuada com o aumento da temperatura e do $\mathrm{pH}^{1}$.

Quanto aos aspectos toxicológicos, o glifosato é irritante dérmico e ocular, podendo causar danos hepáticos e renais quando ingerido em doses elevadas. O composto é absorvido por via oral e dérmica, sendo excretado principalmente na urina. A excreção biliar, no entanto, é limitada e a eliminação através de ar expirado é muito baixa ${ }^{14}$.

$\mathrm{O}$ uso intenso pode causar danos às plantas que não são alvo da aplicação, aumentando o número de espécies que podem ser afetadas. $\mathrm{O}$ uso repetido tem resultado na maior resistência de ervas daninhas através dos mecanismos da seleção natural ${ }^{1,2,14}$, que beneficia biótipos resistentes, preexistentes na população, levando ao aumento da quantidade destes indivíduos. Em consequiência, a população de plantas resistentes pode aumentar a ponto de comprometer o nível de controle das ervas ${ }^{14}$. A toxicidade do glifosato em mamíferos e pássaros é relativamente baixa. No entanto, sendo não seletivo, o largo espectro de atividade do herbicida conduz à destruição de ambientes naturais e de fontes de alimento de alguns pássaros e anfíbios, levando à redução das populações. Um exemplo extremo é uma espécie de sapo da região de Houston, considerada espécie em perigo de extinção devido à destruição de seu habitat pelo glifosato ${ }^{1}$.

Os peixes e os invertebrados aquáticos são os mais sensíveis a este herbicida e aos outros componentes de seus produtos comerciais. Em estudos recentes, onde vários herbicidas foram avaliados quanto a sua ação sobre microorganismos, observou-se que o glifosato apresenta a segunda maior toxicidade para bactérias e fungos, apresentando, ainda, efeitos adversos em alguns invertebrados do solo, incluindo ácaros ${ }^{1}$.

\section{EFEITO AO AMBIENTE}

Quando no ambiente, glifosato tende a ser inativo em contato com solo, desde que seja adsorvido por este. O mecanismo não é inteiramente compreendido. No entanto, supõem-se ligações similares às do fosfato inorgânico. A competição com fosfato inorgânico tem sido demonstrada em laboratório mas não tem sido medida no campo. Íons específicos $\left(\mathrm{Fe}^{2+}, \mathrm{Fe}^{3+}, \mathrm{Al}^{3+}\right)$ complexam-se com glifosato, e os complexos de metal com ácidos húmicos em solo podem ser um mecanismo de ligação deste às partículas do solo ${ }^{2}$. O composto livre no solo é degradado rapidamente a dióxido de carbono, pela atividade microbiana, enquanto que o glifosato adsorvido é degradado mais lentamente, ou não degradado, persistindo inativo durante anos. O herbicida tem sido relacionado à inibição da fixação anaeróbica de nitrogênio no solo ${ }^{1}$.

Devido à rápida adsorção no solo, o glifosato não é facilmente lixiviado, sendo pouco provável a contaminação de águas subterrâneas. Em raras ocasiões, o pesticida tem sido detectado em amostras de águas mas, em geral, isto ocorre devido à dificuldade de separação do composto e também devido ao fato de não ser considerado um sério contaminante aquático ${ }^{1}$. O glifosato é um composto extremamente polar, sendo extraído das amostras aquosas juntamente com cátions metálicos e ânions inorgânicos, o que dificulta sua extração. Por não conter grupos cromóforos, glifosato não absorve radiação eletromagnética visível, não sendo detectado por métodos colorimétricos ou fluorescência, a não ser de forma indireta ou com devida derivatização. Em estudos recentes, novos métodos têm sido desenvolvidos, na tentativa de melhorar a determinação do herbicida em diferentes matrizes ${ }^{1}$.

No caso do uso em água, o glifosato pode ser adsorvido pelos sedimentos, sendo carregado por estes ${ }^{1}$. Esta partição é normalmente rápida e ocorre dentro de 14 dias $^{2}$, ocasionando um processo natural de degradação bem mais lento ${ }^{1}$.

A degradação do glifosato no solo pode seguir duas rotas. A primeira consiste na transformação do glifosato em sarcosina por ação da bactéria Agrobacterium radiobacter ou da Enterobacter aeroneges (enzima C-P liase): a sarcosina entra no metabolismo destes microorganismos e de outros, degradando-se ${ }^{14-16}$. Esta rota é, no entanto, pouco citada na literatura. A segunda rota consiste na transformação do glifosato em ácido aminometilfosfônico, AMPA, conforme apresentado na Figura 3.

Os principais mecanismos de adaptação que podem conferir resistência das ervas aos herbicidas são: alteração do local de ação, metabolismo e compartimentalização do herbicida. Podem ocorrer, ainda, as chamadas resistências cruzada e múltipla. A resistência cruzada ocorre quando um biótipo é resistente a mais de um herbicida com apenas um mecanismo de ação, enquanto que a resistência múltipla ocorre nas plantas que possuem dois ou mais mecanismos distintos. Neste caso, são resistentes a herbicidas de diferentes grupos químicos e com diferentes mecanismos de ação ${ }^{18}$.

O glifosato inibe a enzima 5-enolpiruvoilshikimate-3-fosfato sintase (EPSPs), do mesmo modo que o sulfosato. Estes herbicidas agem pela inibição na rota de síntese dos aminoácidos aromáticos essenciais, fenilalanina, tirosina e triptofano, os quais são precursores de outros produtos, como lignina, alcalóides, flavonóides e ácidos benzóicos. Os sintomas de sua ação sobre as plantas incluem "amarelamento" dos meristemas, necrose e morte em dias ou semanas ${ }^{18}$.

Por apresentarem mais de um mecanismo de ação, além de limitado metabolismo pelas plantas e baixo efeito residual, glifosato e sulfosato apresentam baixa probabilidade na seleção de biótipos resistentes. Apenas um caso de resistência às glicinas foi observado ${ }^{14}$, enquanto que para outros herbicidas, tais como triazinas, foram detectadas 64 espécies com resistência ${ }^{14}$. 


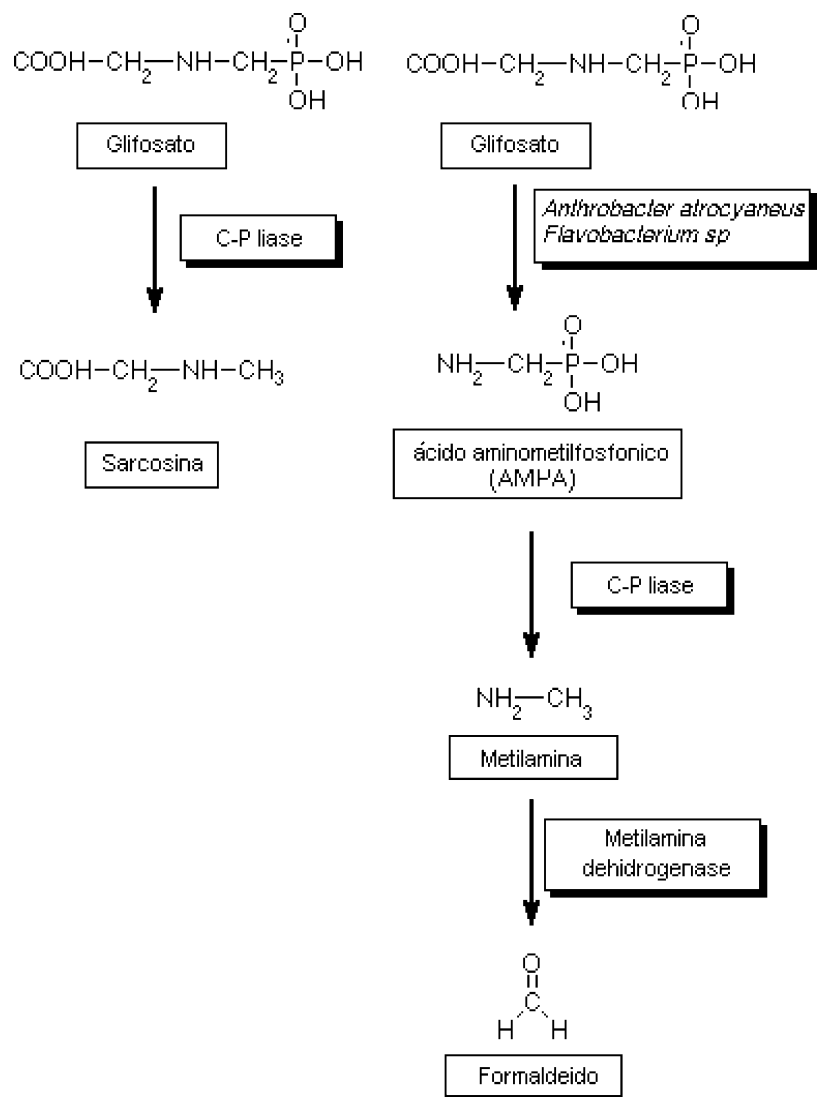

Figura 3. Rotas de decomposição microbiológica do glifosato $^{15-17}$

\section{LEGISLAÇÃO}

Em âmbito nacional, não há limites legais estabelecidos para glifosato em águas ou solo. A Agência de Proteção Ambiental dos Estados Unidos (US EPA) estabelece limite de $700 \mu \mathrm{g} / \mathrm{L}$ de glifosato em água potável como "limite consultivo de saúde"19. Entretanto, a Comunidade Econômica Européia (EEC) estabelece como "concentração máxima admissível" para pesticidas em água potável, como substâncias individuais, o limite de $0,1 \mu \mathrm{g} / \mathrm{L}$, desde que a concentração total de pesticidas não ultrapasse $0,5 \mu \mathrm{g} / \mathrm{L}^{20}$.

A quantidade máxima de resíduo de determinado pesticida que pode ser aceita em cada alimento destinado ao consumo humano é chamada de Limite Máximo de Resíduo (LMR). Estes limites são estabelecidos pelo "Codex Alimentarius Commission", um corpo subsidiário da FAO (Food and Agriculture Organization) e da $\mathrm{WHO}^{21}$. Na legislação brasileira os pesticidas têm seus LMR, ou tolerância, e intervalo de segurança, ou carência (intervalo entre a aplicação do pesticida e a colheita), estabelecidos pela Agência Nacional de Vigilância Sanitária (ANVISA) e seus valores são apresentados na Tabela $1^{22,23}$

Os países integrantes da EEC têm estabelecido LMR de glifosato para frutas e hortaliças $(0,10 \mathrm{mg} / \mathrm{Kg})$, para cogumelos selvagens $(50,00 \mathrm{mg} / \mathrm{Kg})$ e para tubérculos $(0,10 \mathrm{mg} / \mathrm{Kg})^{24}$.

Não existe legislação brasileira que defina limites máximos de resíduos para qualquer pesticida em solos, entretanto, a legislação estabelece normas e critérios para a realização de testes preliminares para a avaliação ecotoxicológica de pesticidas. Estes testes consistem em estudos de biodegradabilidade, adsorção/dessorção e mobilidade. Estudos que avaliem o comportamento e destino dos pesticidas
Tabela 1. Limites de tolerância e intervalos de segurança para glifosato em alimentos, estabelecidos pela ANVISA ${ }^{22,23}$.

\begin{tabular}{|c|c|c|}
\hline Alimentos & Tolerância & Intervalo de segurança \\
\hline \multicolumn{3}{|l|}{ Frutos } \\
\hline $\begin{array}{l}\text { Ameixa, citrus, } \\
\text { maçã, nectarina, } \\
\text { pêra, pêssego, uva. }\end{array}$ & $0,2 \mathrm{ppm}$ & 15 dias \\
\hline Banana & $0,02 \mathrm{ppm}$ & 15 dias \\
\hline \multicolumn{3}{|l|}{ Cereais } \\
\hline Arroz (grão) & $0,2 \mathrm{ppm}$ & ND* \\
\hline Arroz com casca & $0,5 \mathrm{ppm}$ & ND* \\
\hline Arroz (farelo) & $1,0 \mathrm{ppm}$ & $\mathrm{ND}^{*}$ \\
\hline Milho & $0,1 \mathrm{ppm}$ & ND* \\
\hline Trigo & $0,05 \mathrm{ppm}$ & ND* \\
\hline \multicolumn{3}{|l|}{ Sementes oleaginosas } \\
\hline Algodão & $3,0 \mathrm{ppm}$ & 45 dias \\
\hline Soja & $2,0 \mathrm{ppm}$ & 45 dias \\
\hline \multicolumn{3}{|l|}{ Outros produtos } \\
\hline Café (grão) & $1,0 \mathrm{ppm}$ & 15 dias \\
\hline Cacau & $0,1 \mathrm{ppm}$ & 30 dias \\
\hline Cana-de-açúcar & $1,0 \mathrm{ppm}$ & 30 dias \\
\hline Pastagens & $0,2 \mathrm{ppm}$ & $\mathrm{ND}^{*}$ \\
\hline Seringueira & $\begin{array}{l}\text { Uso não } \\
\text { alimentar }\end{array}$ & ND* \\
\hline $\begin{array}{l}\text { Limite de resíduo } \\
\text { não intencional }\end{array}$ & & \\
\hline $\begin{array}{l}\text { Fígado e rim bovinos, } \\
\text { caprinos e aves }\end{array}$ & $0,1 \mathrm{ppm}$ & - \\
\hline
\end{tabular}

$\mathrm{ND}^{*}=$ intervalo de segurança não determinado devido a modalidade de emprego, plantio direto e quebra de dormência.

em solos de regiões tropicais são limitados em relação àqueles efetuados em regiões de clima temperado. Alguns países definem valores de segurança para alguns ingredientes ativos, de modo que quando se possui concentrações superiores às estabelecidas é necessário tomar medidas corretivas ${ }^{25}$.

As águas são divididas em classes pela resolução n. ${ }^{\circ} 20$ de 18 de junho de 1986 do Conselho Nacional do Meio Ambiente (CONAMA) ${ }^{26}$, órgão do Ministério do Meio Ambiente (MMA) e tem limites máximos de resíduos estabelecidos para alguns compostos. Esta resolução traz compostos que já têm seu uso proibido no Brasil, não citando muitos de ampla utilização, dentre estes o glifosato.

\section{CONCLUSÕES}

O glifosato apresenta propriedades muito características, diferentes da maioria dos outros pesticidas estudados; estas dificultam seu monitoramento em amostras ambientais, embora em amostras biológicas $^{27-30}$ e vegetais ${ }^{28,31-35,}$, sua extração tenha sido realizada com maior facilidade. Entretanto, muitos trabalhos têm sido realizados em função de sua ampla utilização. Devido a suas propriedades herbicidas de amplo espectro, isto é, por ser não-seletivo, sistêmico e pouco tóxico a animais, como discutido, tornou-se o mais utilizado no mundo, aumentando a necessidade de implementação de programas de monitoramento, considerando-se a inexistência de legislação que estabeleça limites de glifosato em água e solo. Fazem-se necessários, ainda, investigações que estabeleçam métodos suficientemente validados, que contenham informações tais como limites de detecção e quantificação, recuperações em diferentes níveis de fortificação, entre outras, para serem aplicados a estes programas. 


\section{REFERÊNCIAS}

1. http://www.usfumigation.org/Chemical_Herbicides/Glyphosate/ glyphosate.htm, acessada em Maio 2002.

2. World Health organization. Em Glyphosate: Environmental Health Criteria 159; Genebra: WHO, 1994.

3. British Crop Protection Council. Em The Pesticide Manual: Incorporating the Agrochemicals Handbook; 10 ed., Surrey: Tomlin, 1994.

4. Pastore, P.; Lavagnini, I.; Boaretto, A.; Magno, F.; Anal. Chim. Acta 1990, 230, 29.

5. Mallat, E.; Barceló, D.; J. Chromatogr., A 1998, 823, 129.

6. Wauchope, D. J.; J. Agric. Food Chem. 1976, 24, 717.

7. Harris, D. C.; Quantitative Chemical Analysis, 4 ed., Freeman: New York, 1995.

8. Cikalo, M. G.; Goodal, D. M.; Mathews, W.; J. Chromatogr., A 1996, 745, 189.

9. http://www.agro-fauna.com.br/Produtos_Info.asp?ID=198, acessada em Maio 2002.

10. http://www.usfumigation.org/Literature/Scientific\%20Papers/ glyphosate_fact_sheets.htm, acessada em Maio 2002.

11. http://www.agro-fauna.com.br/Produtos_Info.asp?ID=195, acessada em Maio 2002

12. http://www.agro-fauna.com.br/Produtos_Info.asp?ID=196, acessada em Maio 2002.

13. http://www.agro-fauna.com.br/Produtos_Info.asp?ID=197, acessada em Maio 2002.

14. http://www.nortox.com.br/produtos/bulas/glifosato_na.htm, acessada em Maio 2000.

15. http://umbbd.ahc.umn.edu/gly/gly_map.html, acessada em Maio 2002.

16. http://umbbd.ahc.umn.edu: $8015 / \mathrm{umbbd} / \mathrm{servlet} / \mathrm{pageservlet?}$ ptype $=c \&$ compID $=c 0134$, acessada em Maio 2002 .
17. http://umbbd.ahc.umn.edu/C1cyc/C1cyc_map.html, acessada em Maio 2002.

18. http://www.biotecnologia.com.br/bio/bio18/2.asp, acessada em Maio 2002.

19. Barceló, D.; J. Chromatogr. 1993, 643, 117.

20. International Association of Environmental Analytical Chemistry; Em Sample Handling of Pesticides in Water; Active: Barcelona, 1994.

21. Nunes, G. S.; Ribeiro, M. L.; Pesticidas: Rev. de Ecotox. e Meio Amb. 1999, 9,31 .

22. http://www.anvisa.gov.br/alimentos/tox/mono/g01.htm, acessada em Janeiro 2001.

23. http://www.anvisa.gov.br/consulta/117_2000.htm, acessada em Janeiro 2001.

24. Centre Français du Commerce Extérieur; Em Les Residus de Pesticides dans les Fruits et Legumes et les Pommes de Terre dans les Pays d'Europe Occidentale; CFCE: Paris, 1999, v. 2.

25. Polese, L.; Tese de Doutorado, Universidade Estadual Paulista, Brasil, 2001.

26. http://www.mma.gov.br/port/CONAMA/res/res86/res2086.html, acessada em Janeiro 2001

27. Friestad, H. O.; Broenstad, J. O.; J. Assoc. Off. Anal. Chem. 1985, 68, 76.

28. Alferness, P. L.; Iwata, Y.; J. Agric. Food Chem. 1994, 42, 2751.

29. Powell, H. A.; Kerby, N. W.; Rowell, P.; J. Chromatogr. 1990, 502, 201.

30. Hilda, M.; Mitsui, T.; Fujimura, Y.; Bunseki Kagaku 1989, 38, 87.

31. HOLANDA; General Inspetorate for Health Protection. Ministery of Public Health. Glyphosate; Em Analytical Methods for Pesticides Residues in Foodstuffs; 6 ed., 1996, parte II, p. 1.

32. Thompson, D.G.; Cowell, J.E.; J. AOAC Int. 1989, 72, 355.

33. Tuinstra, L. G. M. T.; Kienhuis, P.G.M.; Chromatographia 1987, 24, 696

34. Tsuji, M.; Aliyama, Y.; Anal. Sci. 1997, 13, 283.

35. Kataoka, H.; Ryu, S.; J. Chromatogr., A 1996, 726, 253. 